\title{
Adding Social Elements to Game-Based Learning
}

\author{
http://dx.doi.org/10.3991/ijet.v9i3.3294 \\ Chien-Hung Lai, Yu-Chang Lin, Bin-Shyan Jong and Yen-Teh Hsia \\ Chung Yuan Christian University, Taoyuan, Taiwan
}

\begin{abstract}
Game-based learning is to present the instruction by games in learning, with the main purpose of triggering learners' motives instead of instructing the courses. Thus, increasing learning motive by game-based learning becomes a common instructional strategy to enhance learning achievement. However, it is not easy to design interesting games combined with courses. In 2011, Echeverria proposed a design to combine characteristics of games with elements of courses by matching the virtual scenarios in games with proper courses. However, in the past game-based learning, students were gathered in regular places for several times of game-based learning. Students' learning was limited by time and space. Therefore, for students' game-based learning at any time and in any places, based on theories of design elements of online community game Aki Järvinen, this study treats Facebook as the platform of games. The development by online community game is easier, faster and cheaper than traditional video games. In 2006, Facebook allowed API program of the third party. Therefore, by Facebook, this study provides the platform for students to learn in social lives to explore students' activities in online community games. Questionnaire survey is conducted to find out if the design of non-single user game is attractive for students to participate in game-based learning. In order to make sure that the questionnaires can be the criteria to investigate students' intention to play games, by statistical program of social science; this study validates reliability and validity of items of questionnaire to effectively control the effect of online community games on students' learning intention.
\end{abstract}

Index Terms-Social Network game, Facebook, game-based learning.

\section{INTRODUCTION}

Game-based learning has been proven to be a kind of learning method that allows students to organize knowledge through the game content in the game process and in turn elevate learning motivation [1]. Compared to traditional education in which students passively receive knowledge, game-based learning allows students to actively participate in game activities [2], which not only strengthens but also maintains student learning motivation, making them willing to spend time on learning [3]. However, in view of the fact that it is not easy to design a system that combines game elements and course content, Echeverria proposed the design method for course knowledge systems, combining game elements and course knowledge. The fictional story of the story or the interaction with fictional characters corresponds to suitable course content, in turn combining the course and the game [4]. However, since traditional game-based learning tends to cause temporal and spatial constraints for students, in order to break through these constraints, so that students can conduct game-based learning at any time and place, this study uses Aki Järvinen's theory of social network game design elements as the basis to create the game in Facebook [5]. Other than using the 2006 feature of Facebook that permits third party development of apps, at the same time the development of social network games is relatively simpler than traditional video games, as well as faster and cheaper. Facebook provides a platform for students to learn as they socialize, and this is used to explore the activity process of students in social network games, further using questionnaires to explore whether the design of social network games can attract students to conduct game-based learning. In order to understand the gaming intentions of students, this study also uses SPSS to conduct reliability and validity testing on questionnaire questions, in hopes of understanding how social network games affect the learning intentions of students.

\section{RELATED WORK}

\section{A. Social Network Game}

The popularity of social network websites has motivated not only how people interact but also greatly influenced the gaming industry. Users only need to use social network websites to publish game information and play games, so the convenience of social network games has become a reason players choose them. Popular social network games even have millions of players [6][7]. In addition, since social network games are created on social network websites, compared to multi-person online games, in which users mostly encounter strangers, in social network games most players are friends in the social network [8], so interacting with friends in games, like working together in missions, or competing with each other can better elevate the fun of gaming.

Social network games generally have the following characteristics:

\section{1) Free}

Most online games on the market require users to pay money each month to play, but in social network games, users can play for free and flexibly choose when they want to play, achieving the game model of easy in easy out [8].

\section{2) Asynchronous}

In most online games, interaction requires being online at the same time, but social network games do not have this limit, and users can asynchronously interact with friends. Thus, when users interact with friends (i.e.: challenge), the friends do not have to be online at the same time, but the system would transmit the interactive messages, and when they come online they can respond to interact. Asynchronous mechanisms mean that users do not have to be online at the same time but they can still enjoy the fun of playing together [5]. 


\section{3) Play limit}

Since social network games have limits in action instances, users cannot finish what they want to do in one sitting, but need to wait for time to pass to restore the play limit. Although this makes users feel like the game has been interrupted, they are not immersed in it, and can use spare time to play. After they have used up their play limit, and when they wait for responses, they can do other things. This can increase the frequency of return to the online system [5].

In terms of game development, compared to traditional video games with beautiful images and realistic sound effects to attract players, the development of social network games is relatively simple, but its fast and cheap characteristics [9] still attract many users who choose social network websites to serve as game development platforms.

\section{B. Design of social network games}

Traditional game design usually focuses on game content and rules, but the design of social network games includes the element of interaction with friends, so interactive mechanisms are an important part of design for social network games. Thus, in social network game design, Aki Järvinen proposed five important design points [5]:

\section{1) Symbolic Physicality}

In the process of gameplay, interaction between characters is frequently expressed in language or action, so in order to give players realistic feelings, game buttons and action design are important. For instance, in the game the "high-five" function occurs when the user clicks a button with friends, which can make them feel that they are giving each other high-fives.

\section{2) Spontaneity}

When actions are reflected in real life, it tends to seem complex and difficult for users to understand, so it is necessary to design interfaces that are easily accepted by users, such as simplifying a series of complex actions into one or two button-presses, or designing games similar to the lives of users, so that designers do not need to explain the game rules too much but still let the users quickly know how to play.

\section{3) Inherent Sociability}

The fun of social network games is generally based on interaction between players and members of their social circles (such as: classmates, colleagues), it is necessary for social network game design to consider how to increase mechanisms for interaction with friends (such as: challenging each other, helping) and to allow players to invite more friends to expand their circle of friends.

\section{4) Narrativity}

Messages allow players to understand their conditions in real time, and at the same time know about the conditions of friends in the game. This can also attract users who do not play the game but check the status updates of friends for effective promotion.

\section{5) Asynchronicity}

Asynchronous game design enables players to not miss important messages due to sudden events (such as: mealtime, showers, sending and receiving E-mail). Social network websites would use emails or messages to save game information, and when players are online they can check email or messages, to understand what happened when they were offline. Asynchronous mechanisms allow players to freely choose when they play, and they do not have arrange a time before playing.

\section{SOCIAL NETWORK GAME LEARNING SYSTEM}

In order to establish the "social network games learning system" on the basis of curricular elements, and at the same time strengthen student impression of course content, the adventure game element is added. Students can engage in adventure and exploration to solve every question in the game step by step. Based on this, the story focus of the game will be on island exploration. When the user first signs into the system, he is asked to name his pet, and when the name is decided, the game begins.

The story of the game begins on a deserted island. The user's pet was abandoned and drifted to this island. The user needs to bring his pet to explore this unknown island, and try to survive under difficult circumstances. The detailed functions and processes of the game are as follows:

Finally, complete content and organizational editing before formatting. Please take note of the following items when proofreading spelling and grammar:

\section{1) Explore the island}

To enable students to become more familiar with the course content through the game, this study uses the instructional materials conceptual diagram for operating systems. The sequence of concepts allows students to gradually increase their familiarity with concepts, but also allows them to use the conceptual diagram to enhance concepts they are less familiar with in the learning process. The areas on the deserted island are the different concepts on operating systems, and arrows are used to guide students in gradually finishing island exploration (based on the conceptual sequence in the conceptual diagram, answer the questions in each concept). However, since game design begins with the concept, before the game begins students still must understand the knowledge and principles of the concepts in order to explore the island with their pets. In order to give pets greater ability differences, the system design involves money and experience points (regardless of accuracy) from exploring the island, and when an area is successfully explored (with correct answers), they can also gain OS points. Student will be able to use OS points to trade for feed that can greatly increase pet abilities, and increase the probability of success in fights. However, if they do not successfully explore the region (with incorrect answers), other than being unable to proceed to the next unknown realm, they are also unable to gain OS points. Thus, these game mechanisms can stimulate students in wanting to defeat others in challenges, elevating the number of times one can successfully explore the island, ad can also enhance student familiarity with concepts.

\section{2) Feeding pets}

Feed is the key to determining pet ability and characteristics. If the pets are not fed, it would increase the probability of failure when fighting wild animals on the island, so students must take note of the stomach fullness of their pets. However, in order to prevent students from feeding pets without restriction, the system only permits students to buy feed by answering the questions correctly to earn 
money to buy feed. The system also sets limits on the fullness of pets, students must return online to take note of the fullness value, feeding them at appropriate times to maintain pet movement. In addition, in order to elevate the fun of the game, so students can feel that their pet is unique, so the feed types will be diversified, and students can give pets different types of feed to improve different abilities. At the same time, when the pets reach certain levels, the preferences of feed would also determine how they develop.

\section{QUESTIONNAIRE DESIGN}

This study uses the learning motivation questionnaire to measure student learning motivation, but since the questionnaire does not measure game attraction, this study will design a game questionnaire, the content of which will primarily measure game quality, social interaction, learning activity, and satisfaction. The responses for each question are measured using the Likert 7-point scale, which are highly agree, somewhat agree, agree, neutral, somewhat disagree, disagree, and highly disagree. The second part uses simple answers to measure concrete views of students toward game design. In order to ensure that the game questionnaire can indeed measure the extent to which the game attracts students, the first part of the questionnaire will be used to conduct the pretest in order to delete or amend unsuitable questions and maintain the reliability and validity of the questionnaire. At the same time, we will observe and analyze the learning portfolio in order to understand how students play the games, to ensure that the results of student responses accurately reflect attraction of the game. After the questionnaire is completed after the pretest, we will use this questionnaire for testing game attraction.

In the pretest stage, students first use the social network game learning system, and fill out the questionnaire after the game is over. The responses to the questionnaire undergo factor analysis using Statistical Package for Social Science (SPSS) for data analysis. The data first undergoes KMO measure of sampling adequacy and Bartlett test of sphericity to ensure that the data can be used for factor analysis. After factor analysis, it ensures that the questions are accurately classified within the expected factors; if the expected categories cannot be obtained, unsuitable questions are deleted or amended, again conducting the pretest and factor analysis. This questionnaire uses factor analysis to extract factors for considering factor loading, to ensure that the scale has good construct validity. At the same time, we will also use Cronbach's $\alpha$ to analyze the reliability of various factors to ensure consistency in the scale reliability. The official questionnaire is used to determine the extent to which games are attractive to students. After data analysis, the response content undergoes factor analysis to ensure that the extracted factors have good construct validity and reliable consistency.

\section{EXPERIMENTAL PROCEDURE}

The experiment course is the 2012 Operating Systems, the course content used are the first three chapters on operating systems, which are "introduction to operating systems," "computer system structure," and "operating system structure." The purpose is to analyze whether the course knowledge system on social networking platform Facebook affects student learning motivation. The exper- iment is divided into four steps. The first step is the pretest motivation questionnaire, used to find out student learning motivation before conducting the course knowledge system. The second step is the game-based learning. The third step is the posttest learning motivation questionnaire; pretest and posttest learning motivation questionnaires are compared to analyze changes in student learning motivation after the course knowledge system. The fourth step is the game questionnaire, to find out more about student views toward social network games.

\section{QUESTIONNAIRE ANALYSIS}

98 students participated in this experiment, and 98 questionnaires were retrieved. Analysis is conducted after retrieval. Questionnaire evaluation is conducted using principal component analysis in SPSS. KMO measure of sampling adequacy and Bartlett test of sphericity are first conducted. The KMO value is 0.935 , the Bartlett test of sphericity value is 1750.249 , and significance is 0.000 , which means that this data can undergo factor analysis.

Statistical testing involves using principal component factor analysis to extract common factors. The number of factors is determined by eigenvalues greater than 1 as the standard for extraction. The result is one single principal element, with accumulated explained variance of $69.501 \%$, which means that the principal component analysis can explain $69.501 \%$ of the raw data .935 Bartlett test of sphericity Close to chi-square distribution 1750.249 Degree of freedom 105 Significance .000

Factor analysis shows that each question in the game questionnaire fall into the same dimension, and the corresponding factor loading of each question is greater than 0.6 , which shows that it has good construct validity.

After validity analysis, this study uses Cronbach's $\alpha$ to conduct reliability analysis for internal consistency. The Cronbach's $\alpha$ coefficient is 0.956 , since it is over 0.700 , it means that the 15 questions in the game questionnaire have homogeneity, meaning this scale has reliable consistency.

\section{EXPERIMENTAL RESULT}

The means show that in the posttest stage, learning motivation has a rising trend. In addition, the bar graph of pretest and posttest motivation questionnaire distributed among the students in Figure 1 shows that after social network game-based learning, their learning motivation increased.

The result of students filling out the game questionnaire, from which 98 valid questionnaires were collected. Results show that students approved the images, animation, and sound effects of the social network game, but there are still students who said they would be more attracted to complete the game if the game screens could be improved upon. In terms of game interaction, students believe that winning in fights in island exploration makes them happy, but still hope for improvements in interaction, and also hope to increase interaction with peers. This shows that when students play games, other than increasing their ability in games, they also hope peers can stimulate their improvement.

Results in the game questionnaire also show that students agree with the temporal and spatial convenience brought be building the game in Facebook, so that learning is no longer constrained by time and space. With the 


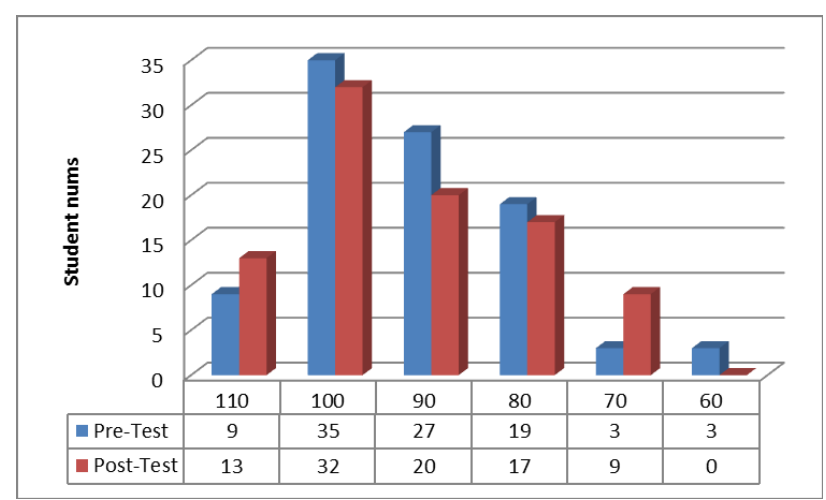

Figure 1. Pretest and posttest motivation questionnaire distributed among the students

TABLE I.

STATISTICS OF GAME BEHAVIOR

\begin{tabular}{|c|c|}
\hline Action & Instances \\
\hline Login game System & 219 \\
\hline Feed Pet & 1118 \\
\hline Pet State & 276 \\
\hline Explore Island & 4495 \\
\hline Answer Question & 1711 \\
\hline
\end{tabular}

assisted learning from the game, it can improve upon boredom while learning, and can also help students review the knowledge they have learned, enhance their understanding of concepts, and in turn decrease their rejection for operating systems.

In addition, this study explores the reason for which students enjoy games on Facebook. Number 13 of the game questionnaire shows that one reason students think Facebook games are fun because of the people playing with them but not because of the game itself. Thus, when more peers are playing the same game, students would become more interested. On the whole, students approved the system, and are happy to recommend it to use by younger students.

Table I is the statistical data on student actions in the social network game learning system, and numbers represent the numbers of times students selected such actions. Since students need to explore the island and answer questions to gain money and experience points, data shows that students spent a lot of time exploring the island. Further, concept completeness shows that out of 98 students, 54 completed all the concepts ("introduction to operating systems," "computer system structure," and "operating system structure"), which shows that without temporal and spatial constraints, students can have sufficient time to engage in game-based learning. Compared to games with time limits, it can enhance student conceptual learning effects.

\section{CONCLUSION}

Statistics on the game questionnaire and experiment data show that students use time effectively to go online for the game, and there are even students who sign into the system early in the morning. This shows that the course knowledge systems on Facebook can indeed make students willing to enter the system to learn after school, to conduct game-based learning without the constraints of time and space. However, this study also finds that in game-based learning, if the same system is used continuously, long time use would result in lowered curiosity or even annoyance at the system, resulting in decreased learning motivation. Thus, the effective addition of new game elements can not only increase student learning motivation but can also help the game to be expressed in more diverse ways.

Questionnaire feedback from students shows that students like social network games because of their peers. Thus, an issue worthy of deep consideration in the future is how to effectively use the characteristics of social network games so that students can also interact with peers while engaging in game-based learning.

\section{REFERENCES}

[1] M. Prensky, "Digital game-based learning," ACM Computers in Entertainment, 1(1), pp. 1-4, 2003. http://dx.doi.org/10.1145/ 950566.950596

[2] D. Burgos, C. Tattersall, and R. Koper, "Re-purposing existing generic games and simulations for e-learning," Computers in $\mathrm{Hu}$ man Behavior, 23(6), pp. 2656-2667, 2007. http://dx.doi.org/ 10.1016/j.chb.2006.08.002

[3] N. Vos, D. M. H. Van, and E. Denessen, "Effects of constructing versus playing an educational game on student motivation and deep learning strategy use," Computers \& Education, 56(1), pp. 127-137, 2011. http://dx.doi.org/10.1016/j.compedu.2010.08.013

[4] A. Echeverria, C. G. Campo, M. Nussbaum, F. Gil, M. Villalta, M. Amestica, and S. Echeverria, "A framework for the design and integration of collaborative classroom games," Computers \& Education, 57(1), pp. 1127-1136, 2011. http://dx.doi.org/10.1016/ j.compedu.2010.12.010

[5] A. Järvinen, "Game Design for Social Networks: Interaction Design for Playful Dispositions," ACM SIGGRAPH Symposium on Video Games, pp. 95-102, 2009.

[6] B. Kirman, S. Björk, S. Deterding, J. Paavilainen, and V. Rao, "Social game studies at CHI 2011," CHI EA'11 Proceedings of the 2011 annual conference extended abstracts on Human factors in computing systems, 2011.

[7] T. Yamakami, "Time management in mobile social game design: Lessons from mobile social games in Japan," Network-Based Information Systems (NBiS), 2011 14th International Conference, pp. 413-418, 2011.

[8] B. Kirman, S. Lawson, and C. Linehan, "Gaming on and off the social graph: The social structure of Facebook Games," International Conference on Computational Science and Engineering, vol. 4, pp. 627-632, 2009.

[9] D.H. Shin, and Y.J. Shin, "Why do people play social network games?" Computers in Human Behavior, 27(2), pp. 852-861, 2011. http://dx.doi.org/10.1016/j.chb.2010.11.010

\section{AUTHORS}

Chien-Hung Lai, Yu-Chang Lin, Bin-Shyan Jong and Yen-Teh Hsia are with Chung Yuan Christian University, Taoyuan, Taiwan.

This article is an extended and modified version of a paper presented at the 2013 Frontiers in Education Conference (FIE2013), held from October 23-26, 2013, in Oklahoma City, Oklahoma, USA. Submitted 30 October 2013. Published as re-submitted by the authors 10 May 2014. 